\title{
İnsansız Hava Aracı ile Ortofoto Üretimi ve Aksaray Üniversitesi Kampüsü Örneği
}

\author{
Hacı Murat Yılmaz ${ }^{*}$, Ömer Mutluoğlu², Ali Ulvi, Aydan Yaman ${ }^{1}$, Süleyman Sefa Bilgilioğlu ${ }^{1}$ \\ ${ }^{1}$ Aksaray Üniversitesi, Harita Mühendisliği Bölümü, 68100, Aksaray \\ (hmuraty@gmail.com, aydan.ketenci@hotmail.com, sefa.bilgilioglu@gmail.com) ORCID ID 0000-0002-9725-5792, \\ ORCID ID 0000-0001-8739-066X, ORCID ID 0000-0002-0881-0396 \\ ${ }^{2}$ Selçuk Üniversitesi, Teknik Bilimler Meslek Yüksekokulu, 42120 Selçuklu, Konya \\ (omutluoglu@ selcuk.edu.tr) ORCID ID 0000-0002-7846-3713 \\ ${ }^{3}$ Selçuk Üniversitesi, Hadim Meslek Yüksekokulu, 42830 Hadim, Konya \\ (aliulvi@selcuk.edu.tr) ORCID ID 0000-0003-3005-8011
}

\section{Öz}

Günümüzde birçok alanda uzaktan algılama ve fotogrametri teknikleri ile üretilen veriler kullanılmaktadır. Gelişen teknoloji ile birlikte günümüzde uzaktan algılama ve fotogrametri ile üretilen verilerde, üretim platformu olarak insansız hava araçları kullanılmaya başlanmıştır. Düşük maliyet, hız, yüksek çözünürlük ve tekrarlı uçuş kabiliyeti sayesinde insansız hava araçları küçük alanlar için tercih edilmektedir. Ayrıca insansız hava araçları, insanların girmesinin tehlikeli olduğu ve hassas davranılması gereken birçok alanda, kolaylıkla ölçüm yapılmasını sağladığı için tercih edilmektedir. Ortofoto görüntü; eğiklik, dönüklük ve yükseklik farkından dolayı meydana gelen hataların düzeltildiği ve dik izdüşüm haline getirildiği sayısal görüntülerdir. Ortofoto görüntüler araziyi birebir olarak temsil ettiğgi için birçok alanda altlık görüntü olarak kullanılmaktadır. Bu nedenle kullanılan ortofoto görüntünün doğruluğu yapılan işin doğruluğuna birebir etki yapmaktadır. Bu çalışmada Aksaray Üniversitesi kampüsünün hava fotoğrafları İnsansız Hava Aracı (IHA) ile çekilmiş ve bu fotoğraflar kullanılarak kampüs alanının ortofotosu elde edilmiştir. Elde edilen sonuçlar insansız hava araçlarının küçük boyutlu alanlar için beklenen doğruluğu sağladığı görülmüştür.

Anahtar kelimeler: Insansı Hava Aracı, Aksaray Üniversitesi, Ü̧̧ Boyutlu Model, Ortofoto

\section{Created Tree Dimensional Model of Aksaray University Campus With Unmanned Aerial Vehicle}

\begin{abstract}
Today, datas generated by remote sensing and photogrammetry techniques are used in most fields. Unmanned aerial vehicles have begun to be used as production platform in data produced with remote sensing and photogrammetry with the developing technology. Thanks to its low cost, speed, high resolution and repeatly flying ability, unmanned aerial vehicles are preferred for small spaces. In addition, unmanned aerial vehicles are preferred for easy measurement in most fields where people's entry is dangerous and must be treated with precision. Ortho photo image is numerical images in which the errors that occur due to the difference in tilt, swing and height difference are corrected and made into a perpendicular projection. Orthophoto images are used in most fields as layout image because represented the field correctly. So, orthophoto image's correctness affects the accuracy of the work done. In this project, the aerial photo graphs of the Aksaray University campus were taken with the Unmanned Aerial Vehicle (UAV) and the orthophotos of the campus are aware obtained using these photographs. The results show that unmanned aerial vehicles provide the expected accuracy for small-sized areas.
\end{abstract}

Keywords: Unmanned Aerial Vehicle (UAV), Orthophoto Image, Oblique Photogrammetry, Digital Photogrammetry

\begin{tabular}{lr}
\hline * Sorumlu Yazar & \\
\hline Geliş Tarihi: 21.12 .2017 & Geomatik Dergisi \\
Kabul Tarihi: 11.01 .2018 & Journal of Geomatics
\end{tabular}




\section{GİRIŞ}

İnsansız hava araçları (İHA) ve sistemleri günümüzde artan bir şekilde tüketici örgütleri, ticari işletmeler ve akademik çevreler tarafindan doğal veya yapay mekânsal objelere ait coğrafi verileri elde etmek amaciyla kullanılmaktadır. Coğrafi veriler, bir koordinat sistemindeki projeksiyon ve datum bilgisine sahip mekânsal bilgileri içeren verilerdir.

Nüfusun artması, arazilerin değerlenmesi, doğal kaynakların azalması ve insan faaliyetlerinin toprak, su ve hava üzerinde oluşturduğu baskı günümüzde çevrenin ölçülüp izlenmesini önemli bir hale getirmiştir. Doğal kaynakların kullanımı, yönetimi ve izlenmesi çalışmalarındaki artışa paralel olarak konumsal referanslı bilgi ihtiyacı da sürekli artmaktadır. Modern yersel, hava ve uydu bazlı teknolojileri kullanarak Coğrafi Bilgi Sistemleri ile birlikte ihtiyaç duyulan veriler daha önce hiç olmadığı kadar hızlı ve doğru bir şekilde toplanmakta, analiz edilmekte ve sonuçlar çeşitli şekillerde sunulabilmektedir.

Son y1llarda ihtiyaç duyulan konumsal verilerin elde edilmesi amaciyla benimsenen yöntemlerden biri de insansın hava araçlarının kullanımıdır. İnsansız Hava Aracı (İHA), bir uçuş planına bağlı olarak otomatik ya da yarı otomatik olarak hareket edebilen veya yerdeki ya da başka bir araç içerisindeki bir pilot tarafindan uzaktan kumanda edilerek uçurulan bir araçtır. İHA sistemleri pilotlu haritalama sitemlerinin yüksek uçuş yüksekliğinden kaynaklanan düşük çözünürlük ve yüksek maliyet kisitlamalarina alternatif olarak kullanılabilmektedir. İHA temelli veri toplama ve haritalama başta tarım, ormancılık, kent planlama, afet yönetimi olmak üzere birçok alandaki çalışmalarda ihtiyaç duyulan yeterli doğruluğu sağlayabilmektedir.

İHA platformu taşıma kapasitesine ve özelliklerine bağlı olarak video kamera, termal ya da kızılötesi kamera sistemleri, multispektral kameralar, LiDAR algılayıcıları veya bu teknolojilerin birkaçını bir arada sunacak şekilde donatılmış olabilir. Ayrıca İHA GNSS/INS (Global Navigation Satellite System/Inertial Navigation System) sistemi, barometrik altimetre ve pusula sistemlerini içerebilir. Böyle entegre bir sistem genellikle İnsansız Hava Arac1 Sistemi (IHS) olarak adlandırılmaktadır.

Konuma dayalı veri üreten Global Konumlama Sistemleri (GPS), yersel jeodezik ölçmeler, LIDAR, yersel lazer tarayıcı, geleneksel hava araçları, fotogrametri ve uzaktan algılama gibi çeşitli yöntemler vardır. İnsansız Hava Araçları (İHA) da konuma dayalı doğru ve hassas veri üretebilen bir teknolojidir. İHA'lar gelecekte birçok disipline veri üreten en önemli veri kaynağı olacaktır (Tahar, 2012).

İHA'ları aerodinamik uçuş prensiplerine göre aralıksız olarak otomatik ya da yarı otomatik uçabilme özelliğine sahip içerisinde uçuş ekibi (pilot) olmadan hareket eden araçlardır. İnsansız Hava Araçları (İHA), uzaktan kontrol edilebilir, yarı otomatik veya tam otomatik tekniklerde uçabilmekte ve kamera, sensör, komünikasyon ekipmanları veya diğer ekipmanları taşıyabilmektedir. İHA'lar klasik insanlı hava taşıtlarından çok daha küçük bir yapıya sahiptir bu nedenle taşıması çok kolay ve daha ekonomiktir. İHA'ların operasyonel savaş güçlerine önemli katkıları da bulunmaktadır (Lucintel, 2011).

Sanal gerçeklik, haberleşme, otomatik yönlendirme gibi uygulamalarda üç boyutlu (3B) model kullanılması gerekmektedir. Örneğin, endüstri kalite değerlendirilmesi sırasında, afet öncesi ve sonrası, turizm, mimarlık alanlarında ve 3B şehir planlamasında binaların 3B modelinin oluşturulması önemlidir. Bu tür çalışmalarda da İHA'lar oldukça etkin ve verimli bir şekilde kullanılmaktadır (Bryson ve Sukkarieh, 2004).

İHA’lar kullanılarak çok alçak uçuşta yüksek hassasiyette elde edilen görüntüler geleneksel hava fotogrametrisinden elde edilen görüntülere göre daha düşük maliyette üretilebilmektedir (Esposito vd., 2014).

$\mathrm{Bu}$ çalışmada, Aksaray Üniversitesi kampüsünde İHA ile gerçekleştirilen uygulamayla, İHS'lerin veri elde etme ve haritalama için sunduğu olanakların ve kısıtlamaların değerlendirilmesi, elde edilen verilerin kullanılabilirliğinin belirlenmesi hedeflenmiştir. $\mathrm{Bu}$ şekilde araziden elde edilecek veriler daha sonra kullanılacak projeler için altlık teşkil edecektir.

\section{INSANSIZ HAVA ARAÇLARI (İHA)}

İnsanız Hava Araçları, boş veya pilotsuz motorlu havasal araçlar olarak tanımlanmaktadır. İHA'ların kontrol mekanizması uzaktan, yarı otomatik, otomatik veya bunların birkaçının birleşiminden oluşmaktadır. İHA'lar diğer hava araçlarıyla karşılaştırıldığında, en önemli fark İHA'larda fiziksel olarak pilotun bulunmamasıdır (Eisenbeiss, 
2004, Rawat ve Lawrence, 2014). İHA'lar, düşük maliyet ile yüksek performansa sahip olmasından dolayı sivil ve askeri amaç ve uygulamalar başta olmak üzere birçok havacılık uygulamalarında en önemli teknolojilerden biridir. İHA'lar kısa kanat açıklığına (sabit veya döner kanatlı) ve hafif bir yapıya sahip olmasının yanında uçuş sırasında da hassas bir yapiya sahiptir (Jung, 2004). Çalıştırılması ve üretilmesi oldukça kolaydır. Bunların birçoğu bir veya iki kişi tarafindan kullanılabilen ve el ile taşınabilen, el ile karadan firlatılabilen bir araçtır. İHA'lar arazide bulunan nesnelerin gözlemlenmesi için düşük yükseklikten uçması için tasarlanmıştır. Fakat çok alçak yükseklikten uçması İHA'nın kaza yapma ihtimalini artırmaktadır. $\mathrm{Bu}$ nedenle düşük yüksekliklerdeki performansın artırılması için güçlü ve doğru otopilot sistemlerine ihtiyac1 vardır (Chao ve Chen 2010).

İHA'lar, termal, kızıl ötesi, hiperspektral, radar, kimyasal ve biyolojik gibi sensörlere sahip çeşitli görüntüleme cihazları ile entegre edilerek gündüz ve gece görüntü alabilme olanağ sağlayabilmektedir. Gerçek zamanlı yer istasyonuna veri transferi özelliği ile birlikte, İHA'lar yangın, sel, hava durumu gibi önemli bilgileri yer istasyonuna aktarabilmektedir (Rawat ve Lawrence, 2014). İHA'lar üzerine entegre edilmiş gerçek zamanlı GPS sistemi ile uçtuğunda ve topladığı görüntüleri gözlemlemek ve yönlendirilmek için yer kontrol istasyonu ile birlikte çalışabilmektedir dolayısı ile bu şekilde çalışan sistemlere tam otomatik navigasyon sistemleri de denilmektedir. Elde edilen görüntü laboratuarda olabildiği gibi anında yer kontrol istasyonunda da işlenebilmektedir. İHA'lar yapmış oldukları tüm hareketleri kayıt altına alabilir ve görüntü işleme de kullanılmak üzere yer kontrol noktalarına iletebilirler (Samad vd., 2013). Fotogrametrik amaçlı İHA'lar bağımsız olarak daha önce planlanmış üç boyutlu konumsal pozisyonlarda fotoğraf çekme yeteneğine sahiptir, fakat uçuş planına uygun kalkış ve iniş için tecrübeli pilotlara ihtiyaç vardır (Graça vd., 2014). Fotogrametri çalışmalarında sıklıkla kullanılan çok döner kanatlı bir İHA Şekil 1' de görülmektedir.

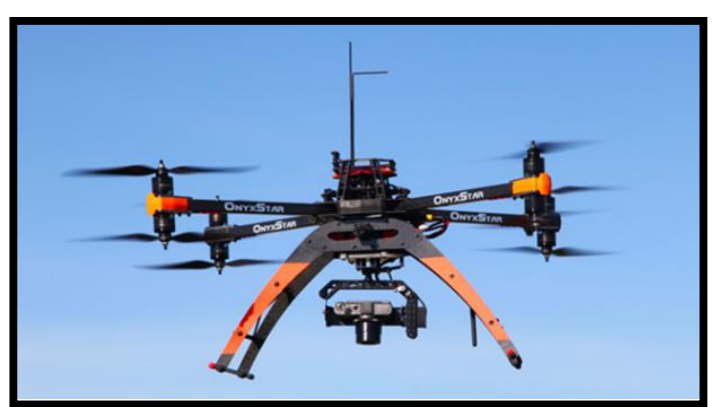

Şekil 1. Döner Kanatlı İHA

İHA'ların birçok avantajı olmasına rağmen dezavantaj1 da vardır. Bunları; Sinırlı yük taşıyabildiklerinden büyük alanları içeren uygulamalarda yetersiz kalmaları, Havada kalma sürelerinin az olması, Rüzgarlı havalarda uygulama yapma imkanının kısıtlı olması, iniş, kalkış ve uçuş aşamasında yaşanan sıkıntılar olarak sıralamak mümkündür.

İHA terimi çoğunlukla haritacılar arasında kullanılmaktadır, fakat kendi itiş sistemleri, irtifa ve dayanıklılık gibi farklı özelliklerine göre farklı terimlere de sahiptir. Bu terimler orijinal isimleri ile birlikte şu şekildedir; Drone, Remotely Piloted Vehicle (RPV), Remotely Operated Aircraft (ROA), Micro Aerial Vehicles (MAV), Unmanned Combat Air Vehicle (UCAV), Small UAV (SUAV), Low Altitude Deep Penetration (LADP) İHA, Low Altitude Long Endurance (LALE) İHA, Medium Altitude Long Endurance (MALE) IHA, Remote Controlled (RC) Helicopter and Model Helicopter. Tüm bu sistemler, hava araci/platformu (İHA), ve Yer Kontrol İstasyonundan (YKİ) oluşmakta ve İnsansız Hava Sistemleri (İHS) olarak bilinmektedir (Nex ve Remondino, 2014).

Bir İnsansız Hava Aracı Sistemi şunları içermektedir;

1. Gerekli ekipmanlar (Sensör vb. ekipman entegreli uçaklar).

2. İletişim Ağı.

3. İHA kullanımı için deneyimli personel.

4. Bazı durumlarda İHA firlatma elemanı (Winnefeld ve Kendall, 2013).

\section{3. ÇALIŞMA ALANI}

$\mathrm{Bu}$ çalışmada çalışma alanı olarak Aksaray Üniversitesi Kampüsü sınırları içinde özellikle yapılaşmanın olduğu bölge kullanılmıştır (Şekil 2). Çalışma bölgesi oldukça düz bir alan olup Kampüs alanı olduğundan oldukça yoğun yapılaşma mevcuttur. 


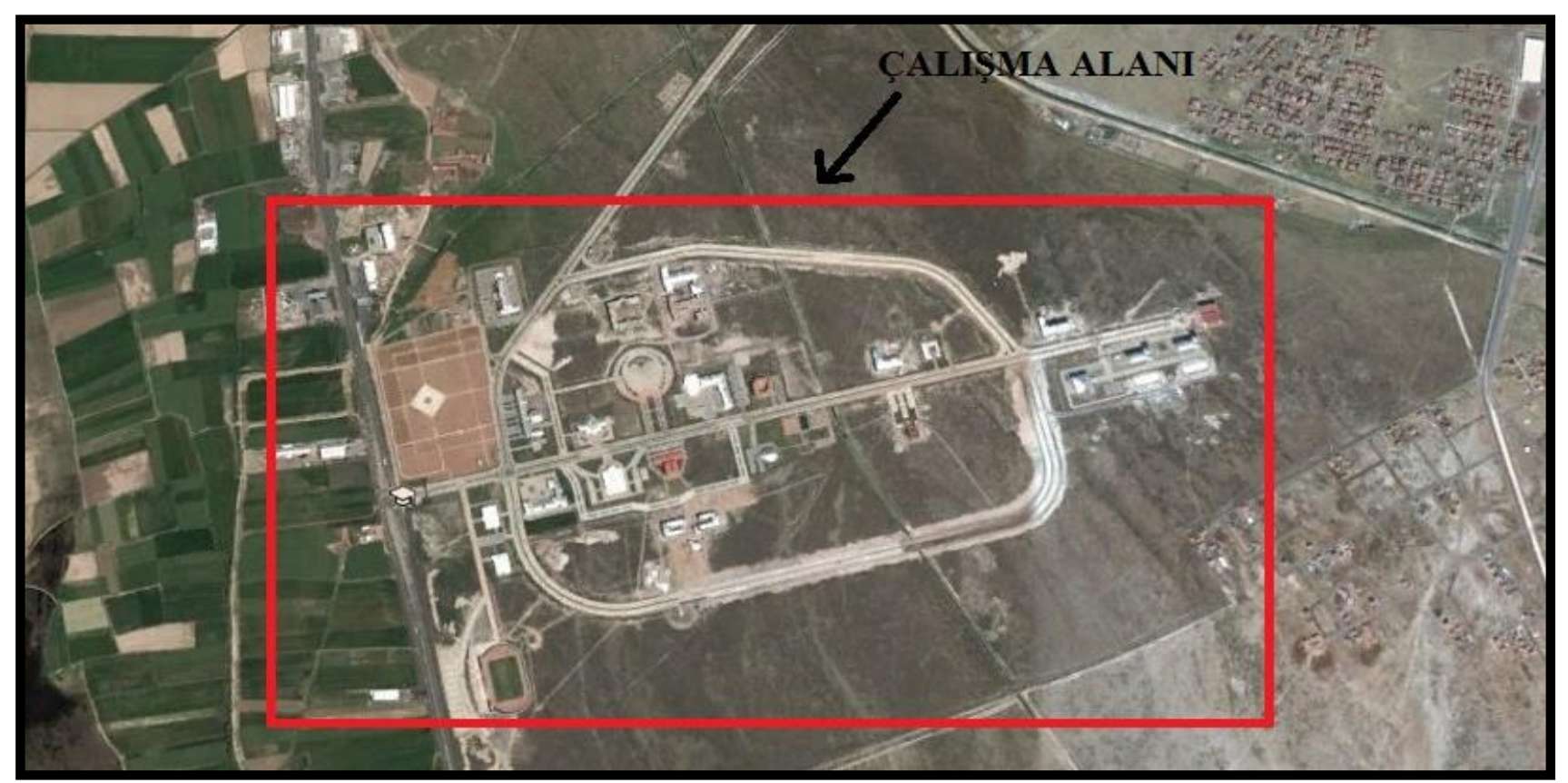

Şekil 2. Aksaray Üniversitesi Kampüsü

\section{MATERYAL VE YÖNTEM}

Çalışma alanı içerisinde bir uçuş planlaması yapılarak gerekli görülen yerlere ve yeteri sıklıkta yer kontrol noktası tesis edilmiştir (Şekil 3). Yer kontrol noktalarının koordinatları WGS84 koordinat sisteminde TOPCON GR3 GPS alıcis1 ile elde edilmiştir (Şekil 4).

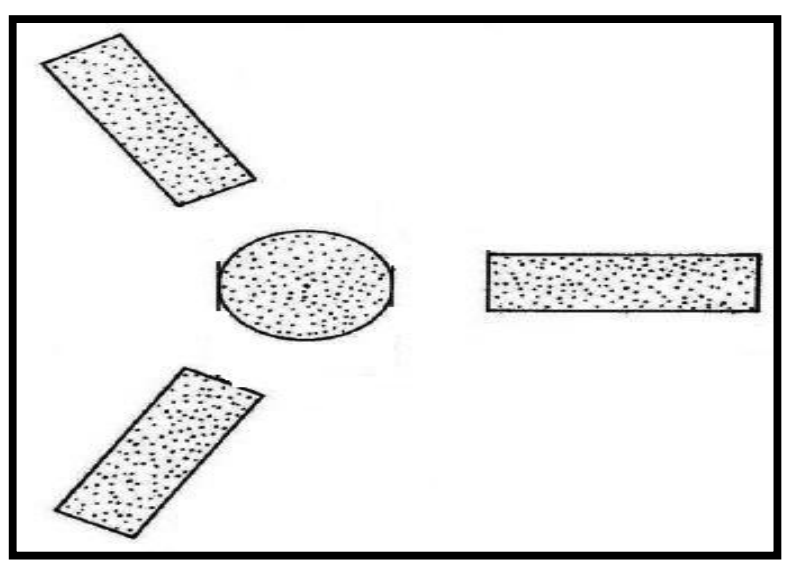

Şekil 3. Kullanılan Yer Kontrol Noktası

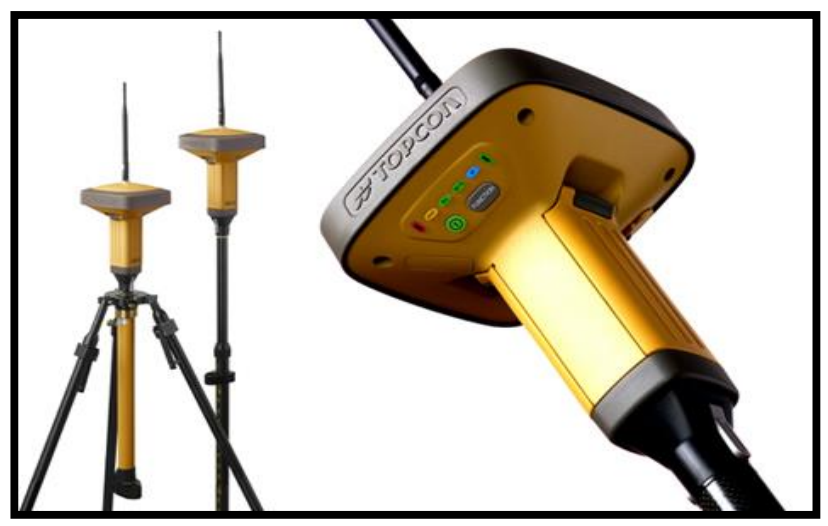

Şekil 4. Çalışmada Kullanılan GPS Alıcısı

Proje çalışmasında resimlerin çekimi için Smartplanes İnsansız Hava Aracı kullanılmış (Şekil 5) ve bu araçta 12 MP çözünürlüklü Ricoh marka kamera kullanılmıştır (Şekil 6).

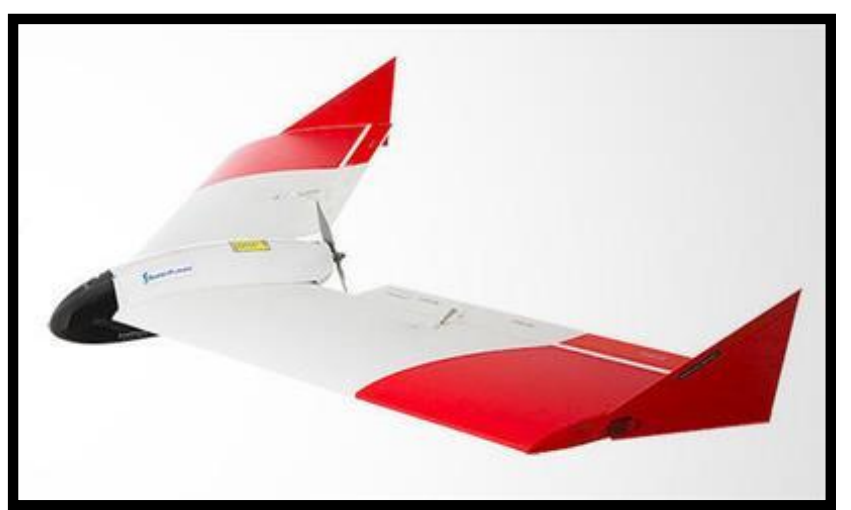

Şekil 5. Çalışmada Kullanılan İnsansız Hava Aracı 


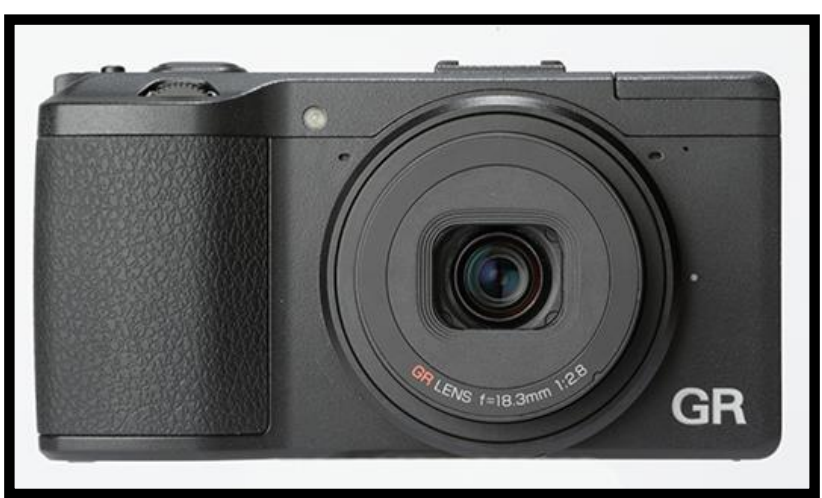

Şekil 6. İnsansız Hava Aracında Kullanılan Kamera

Uçuş planlaması yapılıp arazideki çalışmalar tamamlandıktan sonra uçuş işlemleri yapılmıştır. Uçuş işlemleri tamamlandıktan sonra elde edilen resimlerin değerlendirme işlemleri çalışma kapsamında alınan Virtual Surveyor İHA yazılımında gerçekleştirilmiştir. Uçuş işleminden elde edilen bazı görüntüler Şekil 7'de görülmektedir.

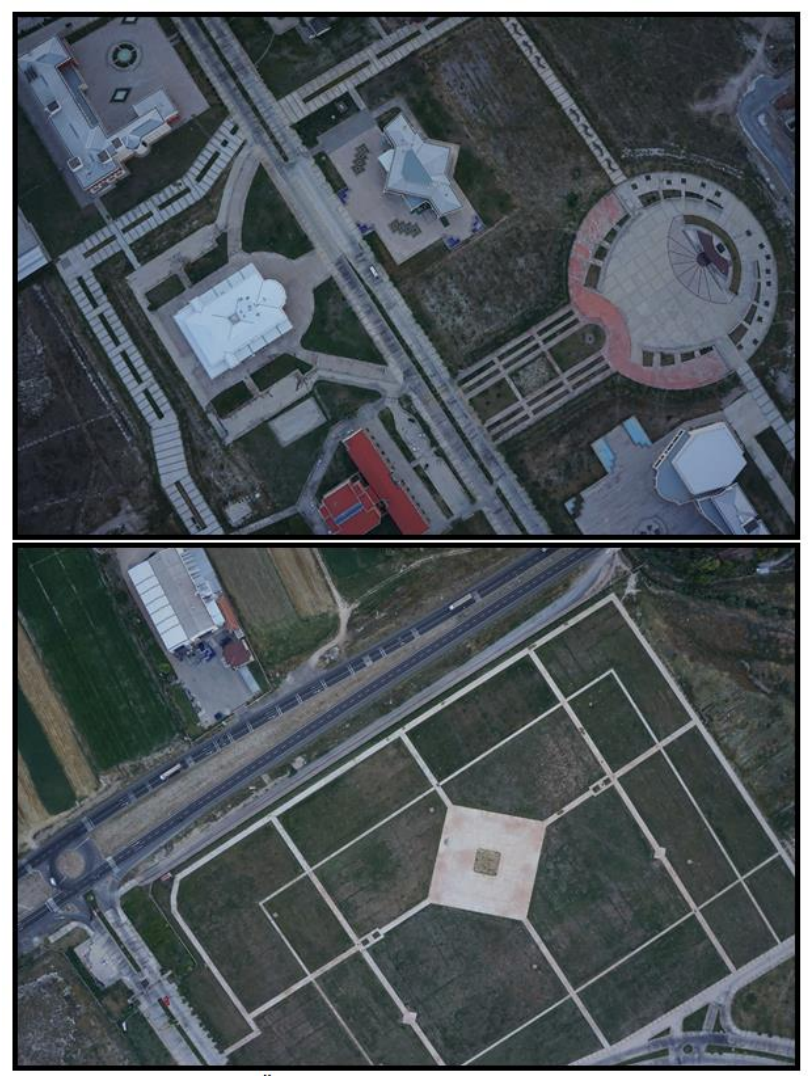

Şekil 7. Aksaray Üniversitesi Kampüs Alanından Görüntüler

\section{ANALIZ VE BULGULAR}

Proje kapsamında elde edilen resimler Virtual Surveyor İHA yazılımında değerlendirildi ve uygulama alanının Sayısal Yükseklik Modeli (SYM) ve ortofoto haritas1 elde edildi. Elde edilen çıktılardan Sayısal Yükseklik Modeli Şekil 8'de, Ortofoto Harita Şekil 9'de ve Eşyükseklik Eğrili harita Şekil 10'de görülmektedir.

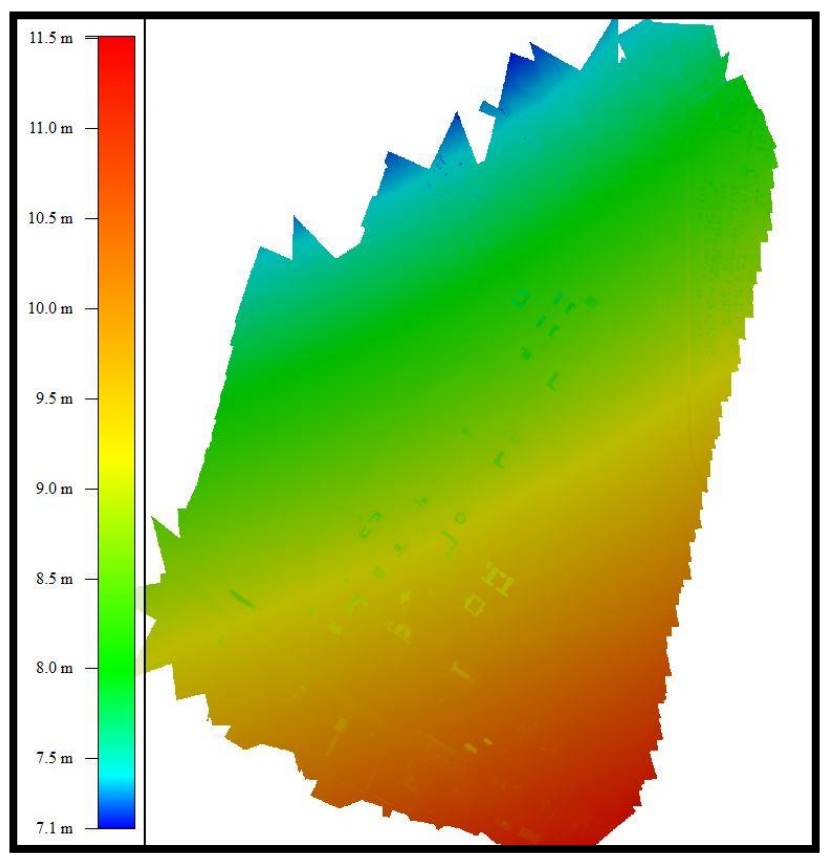

Şekil 8. Sayısal Yükseklik Modeli

Elde edilen ürünlerin doğruluğunu kontrol etmek amaciyla elde edilen üç boyutlu model ve ortofoto harita üzerinde beş noktada yatay uzunluk ve beş noktada özellikle binalarda düşey uzunluklar ölçüldü. Aynı yatay ve düşey uzunluklar arazide jeodezik ölçme aleti Total Station ile de ölçülerek yatay ve düşey uzunluklardaki hatalar elde edildi. Yapılan yatay ve düşey ölçmeler Tablo 1'de verilmiştir. 


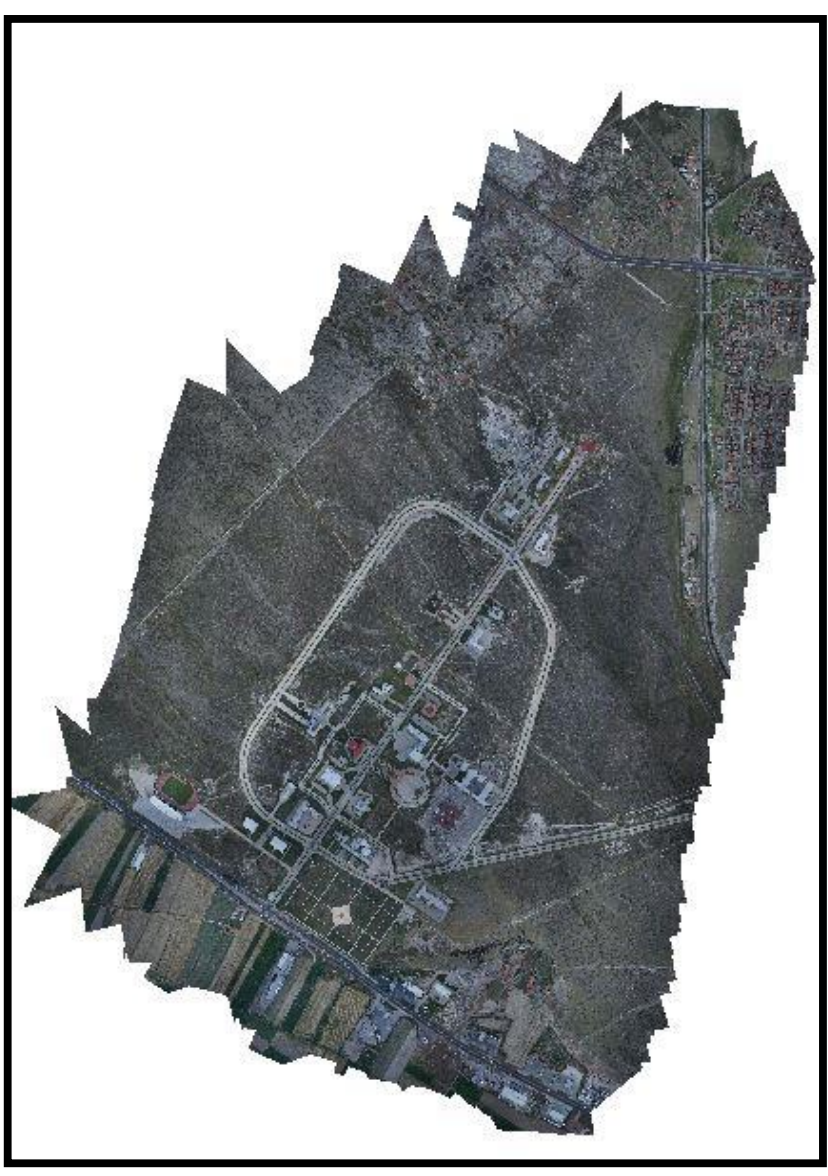

Şekil 9. Ortofoto Harita

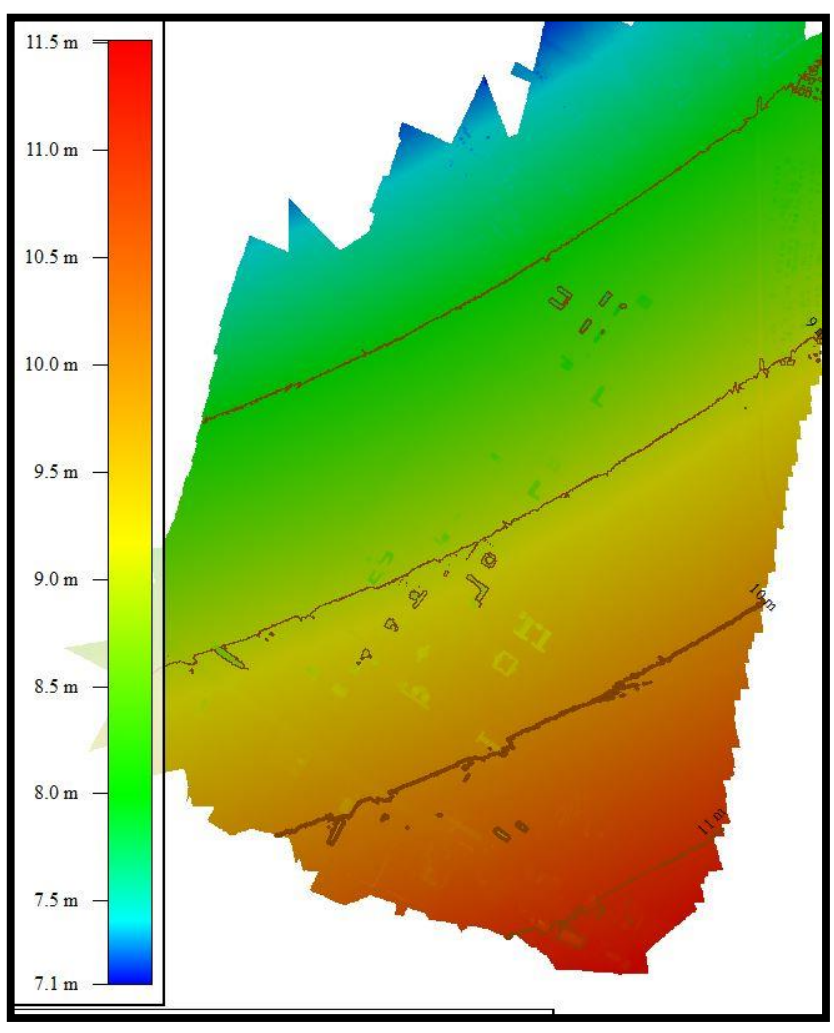

Şekil 10. Eşyükseklik Eğrili Harita

Tablo 1. Ölçülen Yatay ve Düşey Uzunluklar

\begin{tabular}{|c|c|c|c|}
\hline & $\begin{array}{c}\text { Model } \\
\text { üzerinden } \\
\text { Ölçülen } \\
\text { Uzunluk (m) } \\
\end{array}$ & $\begin{array}{l}\text { Yersel Ölçme } \\
\text { Yöntemi ile } \\
\text { Hesaplanan } \\
\text { Uzunluk (m) }\end{array}$ & Farklar (m) \\
\hline \multicolumn{4}{|c|}{ Yatay Uzunluklar } \\
\hline AA & 56.115 & 56.132 & 0.017 \\
\hline BB & 8.435 & 8.411 & 0.024 \\
\hline $\mathrm{CC}$ & 17.893 & 17.913 & -0.020 \\
\hline $\mathrm{DD}$ & 36.512 & 36.484 & 0.028 \\
\hline $\mathrm{EE}$ & 26.406 & 26.421 & -0.015 \\
\hline \multicolumn{4}{|c|}{ Düşey Uzunluklar } \\
\hline $\mathrm{FF}$ & 9.311 & 9.355 & 0.044 \\
\hline GG & 6.744 & 6.779 & 0.035 \\
\hline $\mathrm{HH}$ & 9.782 & 9.823 & 0.041 \\
\hline KK & 9.285 & 9.345 & 0.060 \\
\hline LL & 6.125 & 6.163 & 0.038 \\
\hline
\end{tabular}

\section{SONUÇLAR VE ÖNERILER}

Düşük maliyet ve risk ile herhangi bir insanı, tehlikeli durumlara veya tehlikeli bölgelere sokmadan ulaşılması mümkün olmayan veya tehlikeli bölgelere ulaşması olanağı araştırmacıları klasik hava fotogrametrisine alternatif olarak İHA'lara yöneltmiştir. Bu çalışmada çalışmasından da İHA verileri üç boyutlu model oluşturma ve ortofoto harita elde edilmiștir. Çalıșma sonucunda elde edilen ürünlerdeki konum hatası ortalama \pm $2.38 \mathrm{~cm}$, yükseklik hatası ise ortalama $\pm 9.94 \mathrm{~cm}$ olarak hesaplanmıştır. Çalışılan bölgede kot fark1 1 m 'yi geçmemekle birlikte yapılaşmanın olduğu bir bölgedir. Üç boyutlu modellerin elde edilmesinde düşey resimlerin yanı sıra eğik resimlerinde çekilmesi önem arz etmektedir. Yükseklik doğruluğu bu nedenle konum doğruluğundan daha yüksek çıkmıştır. Klasik hava fotogrametrisine kıyasla küçük alanların halihazır haritalarının, sayısal arazi modellerinin, sayısal yükseklik modellerinin ve birçok disiplin tarafından kullanılan ortofoto haritaların İnsansız Hava Araçları kullanılarak uygun konum ve yükseklik hatalarına sahip, daha kisa sürede ve daha ekonomik olarak üretilebileceği sonucuna varılmıştır.

\section{TEŞEKKÜR}

$\mathrm{Bu}$ çalışma, Aksaray Üniversitesi Rektörlüğü, Bilimsel Araştırma Projeleri Koordinatörlügü tarafindan, BAP 2016-044 kodlu proje ile desteklenmiştir. İlgili birime teşekkürlerimizi sunarız. 


\section{KAYNAKÇA}

Bemis S. P., Micklethwaite S., Turner D., James M. R., Akciz S., Thiele S. T., Bangash H. A., "Groundbased and UAV-Based photogrammetry: A multi-scale, high resolution mapping tool for structural geology and paleoseismology". Journal of Structural Geology 69 (2014) $163 \mathrm{e} 178164$.

Brutto M. L., Garraffa A., Meli P., "UAV Platforms For Cultural Heritage Survey: First Results". ISPRS Annals of the Photogrammetry, Remote Sensing and Spatial Information Sciences, Volume II-5, 2014 ISPRS Technical Commission V Symposium, 23 - 25 June 2014, Riva del Garda, Italy.

Bryson M., and Sukkarieh S., "Vehicle Model-Aided Inertial Navigation for a UAV Using Low-Cost Sensors", in Proc. Australasian Conf. on Robotics and Automation, Canberra, Australia.

Chao, H.,Cao, Y., ve Chen, Y., "Auto pilots for Small Unmanned Aerial Vehicles: A Survey,” Int. J. Control Autom. Syst. 8(1), 36-44 (2010).

Chou T. Y., Yeh M. L., Chen Y. C., Chen Y. H., "Disaster Monitoring And Management By The Unmanned Aerial Vehicle Technology", In: Wagner W., Székely, B. (eds.): ISPRS TC VII Symposium - 100 Years ISPRS, Vienna, Austria, July 5-7, 2010, IAPRS, Vol. XXXVIII, Part 7B.

Chou, T. Y.,Yeh, M. L., Chen, Y. C. ve Chen, Y. H., 2010. Disaster monitoring and management by the unmanned aerial vehicle technology.

Eisenbeis, H., 2009. UAV photogrammetry. Zurich, Switzerland:: ETH.

Eisenbeiş H., "UAV Photogrammetry", Institut für Geodäsie und Photogrammetrie Eidgenössische Technische Hochschule Zürich Wolfgang-PauliStrasse 158093 Zürich, Copyright (C) 2009, Henri Eisenbeiß.

Eisenbeiss, H. (2004) "A mini unmanned aerial vehicle (UAV): system overview and image acquisition". International Archives of Photogrammetry, Remote Sensing and Spatial Information Sciences, vol. XXXVI, part 5/W1, on CD-ROM.

Esposito S., Fallavollita P., Wahbeh W., Nardinocchi C., and Balsi M., "Performance Evaluation Of UAV Photogrammetric 3D Reconstruction". IGARSS 2014.

EuropeanUnion, August 2015. "Space Enabled Applications UAV systems for civilian applications", Business Innovation Observatory Contract No 190/PP/ENT/CIP/12/C/N03C01.

Graça N.,Mitishita E., Gonçalves J., "Photogrammetric Mapping Using Unmanned Aerial Vehicle", The International Archives of the Photogrammetry, Remote Sensing and Spatial Information Sciences, Volume XL-1, 2014 ISPRS Technical
Commission I Symposium, 17 - 20 November 2014, Denver, Colorado, USA.

Greenwood F.,July 2015. "Drones And Aerial Observation: New Technologies For Property Rights, Human Rights, And Global Development", Chapter Number 4, Cover Illustration And Interior Illustrations Are Valerie Altounian.

Grenzdörffer G. J., Engel A., Teichert B. (2008). "The photogrammetric potential of low-cost UAVs in forestry and agriculture". Int. Archives of Photogrammetry, Remote Sensing and Spatial Information Sciences, Beijing, China, 2008 37(B1): 1207-1213.

Haala N, Kada M. "An update on automatic 3d building reconstruction". ISPRS Journal of Photogrammetry and Remote Sensing 65 (2010) 570-580.

Haarbrink R. B., Koers E., "Helicopter UAV For Photogrammetry and Rapid Response", InterCommission WG I/V, Autonomous Navigation 2007.

Haser, A.B., 2010. Bu insansız hava aracından daha önce yapmamış mıydık?, Bilim ve Teknik Dergisi, Aralık sayısı.

Hoffmann, G. M., Rajnarayan, D. G., Waslander, S. L., Dostal, D., Jang, J. S. ve Tomlin, C. J., 2004. The Stanford Testbed Of Autonomous Rotorcraft For Multi Agent Control (Starmac), in 23rd Digital Avionics System Conference, 12.E.4- 121-10.

Jung S., "Design ve Development Of A Micro Air Vehicle (MAV): Test-Bed For Vision-Based Control". Abstract of Thesis Presented to the Graduate School of theUniversity of Florida in Partial Fulfillment of the Requirements for the Degree of Master of Science, December 2004.

Laliberte, A. S., Winters, C. ve Rango, A. 2007. Acquisition, orthorectification, and classification of hyperspatial UAV imagery. In Fourth Annual Symposium: Research Insights in Semiarid Scosystems, RISE, University of Arizona, Tucson.

Li M., Nan L., Smith N., Wonka P., "Reconstructing building mass models from UAV images", Special Issue on CAD/Graphics 2015.

Lucintel, 2011. "Growth Opportunity in Global UAV Market". Accessed July 1, 2012, at www.lucintel.com/LucintelBrief/UAVMarketOp portunity.pdf.

Manyoky M., Theiler P., Steudler D., Eisenbeiss H. (2011) "Unmanned aerial vehicle in cadastral applications". Int. Archives of Photogrammetry, Remote Sensing and Spatial Information Sciences, Zurich, Switzerland, 38 (1/C22).

Nakano T.,Kamiya I., Tobita M., Iwahashi J., Nakajima H., "Land form Monitoring In Active Volcano By UAV and Sfm-Mvs Technique", The International Archives of the Photogrammetry, 
Remote Sensing and Spatial Information Sciences, Volume XL-8, 2014 ISPRS Technical Commission VIII Symposium, $09-12$ December 2014, Hyderabad, India.

Nex F., Remondino F. "UAV for 3D mapping applications: A review", Article in Applied Geomatics, 2014.

Niethammer, U., Rothmund, S. ve Joswig, M., 2009. UAV-based remote sensing of the slow moving landslide Super-Sauze, In: Landslide processes, Ed.: CERG Editions, Strasbourg, 69-74.

Rau, J. Y., Jhan, J. P., Lo, C. F. ve Lin, Y. S., 2011. Landslide mapping using imagery acquired by a fixed-wing UAV, In Proceedings of the International Conference on Unmanned Aerial Vehicle in Geomatics, (Vol. 38, p. 6).

Rawat K. S., Lawrence E. E., "A mini-UAV VTOL Platform for Surveying Applications". International Journal of Robotics and Automation (IJRA) Vol. 3, No. 4, December 2014, pp. 259 267.

Ro K., Oh J. S., ve Dong L., "Lesson sLearned: Application of Small UAV for Urban Highway Traffic Monitoring", 45th AIAA Aerospace Sciences Meeting and Exhibit 8 - 11 January 2007, Reno, Nevada.

Saleri R., Pierrot-Deseilligny M., Bardiere E., Cappellini V., Nony N., De Luca L., Campi M., 2013, "UAV Photogrammetry for archaeological survey: The Theaters area of Pompeii.

Samad A. M., Kamarulzaman N., Hamdani M. A., Mastor T. A. ve Hashim K. A., "The Potential of Unmanned Aerial Vehicle (UAV) for Civilian and Mapping Application", 2013 IEEE 3rd International Conference on System Engineering and Technology, 19 - 20 Aug. 2013, Shah Alam, Malaysia.

Tahar K. N., "A New Approach On Slope Data Acquisition Using Unmanned Aerial Vehicle". IJRRAS 13 (3) December 2012.

Vito, 2009. Vito, UAV Flights corporate web site, Adres: http://isprs.vgt.vito.be/uav/Testflights.html, (accessed June 2 2009).

Winnefeld J. A., Kendall F., "Unmanned Systems Integrated Road map FY2013-2038" Approved for Open Publication Reference Number: 14-S0553. 